\title{
Gamma Radiation Measurements in Tunisian Marbles
}

\author{
Kais Manai ${ }^{1}$, Chiraz Ferchichi ${ }^{1}$, Mansour Oueslati ${ }^{2}$, Adel Trabelsi ${ }^{1,3}$ \\ ${ }^{1}$ Research Unit of Nuclear and High Energy Physics, Faculty of Sciences of Tunis, \\ Tunis El-Manar University, Tunis, Tunisia \\ ${ }^{2}$ National Center for Nuclear Sciences and Technologies, Sidi-Thabet, Tunisia \\ ${ }^{3}$ Physics Department, College of Science, King Faisal University, Hofuf, KSA \\ Email: manai@ipnl.in2p3.fr, adel.trabelsi@cern.ch
}

Received January 5, 2012; revised February 28, 2012; accepted March 9, 2012

\begin{abstract}
The radioactivity of 15 kinds of different granites collected in Tunisia was determined by gamma-ray spectrometry using hyper-pure germanium (HPGe) detector. The average activity concentrations for primordial radionuclides ${ }^{238} \mathrm{U}$, ${ }^{232} \mathrm{Th}$ and ${ }^{40} \mathrm{~K}$ were respectively $33.24,8.01$ and $116.98 \mathrm{~Bq} / \mathrm{kg}$. The activity concentrations ranged from 3.59 to 87.37 $\mathrm{Bq} / \mathrm{kg}$ for ${ }^{238} \mathrm{U}$, from 0.45 to $25.34 \mathrm{~Bq} / \mathrm{kg}$ for ${ }^{232} \mathrm{Th}$ and from 24.06 to $380.23 \mathrm{~Bq} / \mathrm{kg}$ for ${ }^{40} \mathrm{~K}$. The measured activity concentrations were used to assess of the radium equivalent activity ranged from 22.2 to $995.8 \mathrm{~Bq} / \mathrm{kg}$, the absorbed dose rate in air from 7 to $1209 \mathrm{nGy} / \mathrm{h}$ and the internal (0.1 to 2.8) and external (0.1 to 2.7) hazard indices. The data obtained in this study may be useful for natural radioactivity mapping.
\end{abstract}

Keywords: Radioactivity; Marble; Radium Equivalent; External and Internal Hazard Indices

\section{Introduction}

Natural radioactive materials (rocks, soil, sediment, water and aliment) contain low-level radioactivity. Marble used in building and decoration are also possible sources of radioactivity. Radioactivity in the marbles consists of the ${ }^{238} \mathrm{U}$ series [1-3] with a relative abundance of $99.284 \%$ and a half-life of $4.468 \times 10^{9}$ years, the thorium series ${ }^{232} \mathrm{Th}$ with a relative abundance of $100 \%$ and a half-life of $14.05 \times 10^{9}$ years and the actinium series ${ }^{235} \mathrm{U}$ with a relative abundance of $0.716 \%$ and a half-life of $9.47 \times$ $10^{10}$ years. There are also several singly occurring radionuclides, the most important one is ${ }^{40} \mathrm{~K}$ with a relative abundance of $0.0117 \%$ and a half-life of $1.248 \times 10^{9}$ years. The emanation of radon $\left({ }^{222} \mathrm{Rn}\right)$ is associated with the presence of ${ }^{226} \mathrm{Ra}$ and its ultimate precursor ${ }^{238} \mathrm{U}$ in the ground. The inhalation of its short-lived daughter products is a major contributor to the total radiation dose.

The objective of the work is to estimate the radioactivity concentrations of primordial radionuclides; ${ }^{238} \mathrm{U},{ }^{232} \mathrm{Th}$ and ${ }^{40} \mathrm{~K}$ in marble samples collected in Tunisia. The absorbed and effective dose rate, the external and internal hazard indices in marble samples have been determined. The measurements have been carried out using a HPGe spectrometer.

\section{Experimental Setup}

A total of 15 different kinds of marble in Tunisia have been collected. Figure 1 shows the Tunisian states where the commercial marble samples were collected. The samples were pulverised, dry-weighed [4,5], sealed in $1 \mathrm{l}$ plastic Marinelli beakers and stored for 4 weeks in order to allow the reaching of equilibrium between ${ }^{226} \mathrm{Ra}$ and ${ }^{222} \mathrm{Rn}$ and its decay products [6,7].

Spectra for different samples were measured with a hyper-pure germanium (HPGe) detector of high-resolution gamma-ray spectrometer. Figure 2 show a spectrum of Tunisian marble sample 1 . The detector has a photopeak efficiency of $30 \%$ and an energy resolution of 1.85 $\mathrm{keV}$ (FWHM) for the $1.332 \mathrm{MeV}$ reference transition of ${ }^{60} \mathrm{Co}$. The measurements have been carried out at the Center for Nuclear Sciences and Technology, Sidi Thabet, Tunisia $(C N S T N)$.

To obtain the gamma spectrum with good statistics, the accumulation time for each sample is set at 20 hours. Marble samples container were placed inside a shield, in order to minimize the background radiation. The background distribution in the environment around the detector was counted in the same manner and in the same geometry as the samples. It was determined using an empty sealed beaker. The background spectra were used to correct the net peak area of gamma rays of measured isotopes.

\section{Results and Discussion}

\subsection{Calculation of Activity Concentrations}

The specific activity $A_{E_{i}}(\mathrm{~Bq} / \mathrm{kg})$ of a nuclide $i$ and for 


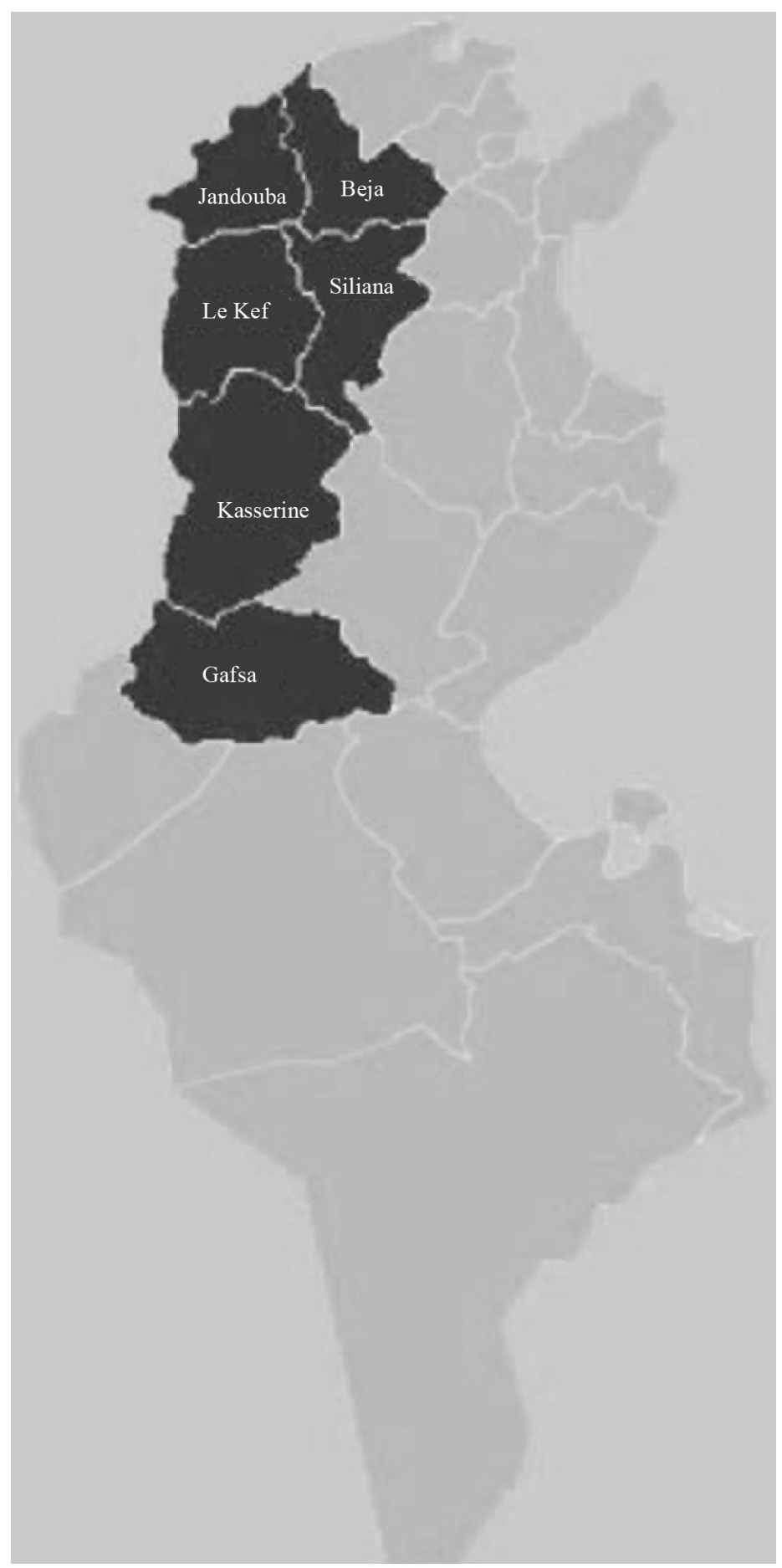

Figure 1. Localization of the Tunisian states where the commercial marble samples were collected.

a peak at energy $E$, is given by:

$$
A_{E_{i}}=N_{E_{i}} /\left(\varepsilon_{E} \times \gamma_{D} \times t \times M_{s}\right)
$$

where $N_{E_{i}}$ is the net peak area, $\varepsilon_{E}$ the detection efficiency at energy $E, \gamma_{D}$ the gamma ray yield per disintegration of the specific nuclide for the transition at energy $E, M_{s}$ the mass of the measured sample $(\mathrm{kg})$ and $t$ the counting live-time (s). If there is more than one peak in the energy range of analysis, then the result is the weighted average nuclide activity.

The gamma-ray transitions of ${ }^{214} \mathrm{~Pb},{ }^{214} \mathrm{Bi}$ were used to determine the concentration of the ${ }^{238} \mathrm{U}$ series. The gamma-ray transitions ${ }^{228} \mathrm{Ac},{ }^{208} \mathrm{Tl}{ }^{228} \mathrm{Ac}$ were used to calculate the concentration of the ${ }^{232} \mathrm{Th}$ series. The gama-ray 


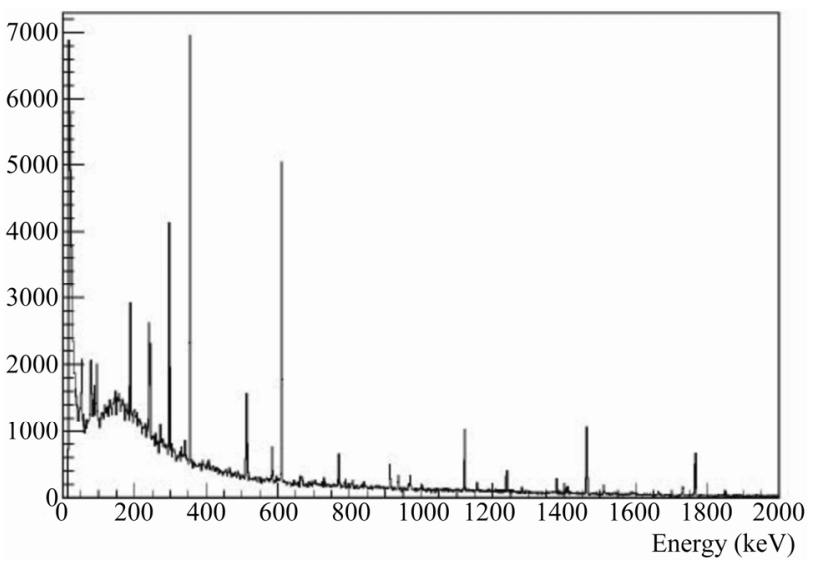

Figure 2. A spectrum of Tunisian marble sample 1.

transition of ${ }^{40} \mathrm{~K}$ was used to determine the concentration of ${ }^{40} \mathrm{~K}$ in different samples.

The activity concentrations of the natural radionuclides of the 15 kinds of marbles are shown in Figure 3. The activity concentrations ranged from 3.59 to $87.37 \mathrm{~Bq} / \mathrm{kg}$ for ${ }^{238} \mathrm{U}$, from 0.45 to $25.34 \mathrm{~Bq} / \mathrm{kg}$ for ${ }^{232} \mathrm{Th}$ and from 24.06 to $380.23 \mathrm{~Bq} / \mathrm{kg}$ for ${ }^{40} \mathrm{~K}$. The average activity concentrations are $33.24 \mathrm{~Bq} / \mathrm{kg}$ for ${ }^{238} \mathrm{U}, 8.01 \mathrm{~Bq} / \mathrm{kg}$ for ${ }^{232} \mathrm{Th}$, and $116.98 \mathrm{~Bq} / \mathrm{kg}$ for ${ }^{40} \mathrm{~K}$.

From the 15 samples measured in this study, Sample (2) appears to present the highest concentrations for ${ }^{238} U$, Sample (11) presents the highest concentration for ${ }^{232} \mathrm{Th}$ and Sample (7) presents the highest concentration for ${ }^{40} \mathrm{~K}$.

\subsection{Absorbed and Effective Dose Rate}

Absorbed dose rate $\mathrm{D}$ (in $\mathrm{nGy} / \mathrm{h}$ ) can be calculated using the following formula $[8,9]$ :

$$
D=A_{E_{i}} \times C_{F}
$$

where $A_{E_{i}}$ is the activity concentration (in $\mathrm{Bq} / \mathrm{kg}$ ), and $C_{F}$ is the dose conversion factor (absorbed dose rate in air per unit activity per unit of soil mass in $\mathrm{nGy} / \mathrm{h}$ per $\mathrm{Bq} / \mathrm{kg})$.

To estimate the annual effective dose, one has to take into account the conversion coefficient from absorbed dose in air to effective dose and the indoor occupancy factor [10]. A value of $0.7 \mathrm{~Sv} /$ year was used for the conversion coefficient from absorbed dose in air to effective dose received by adults, and 0.8 for the indoor occupancy factor, implying that $20 \%$ of time is spent outdoors. The effective dose rate $\left(D_{\text {eff }}\right)$ indoors (in mSv/year), is calculated by the following formula:

$$
D_{\text {eff }}=D \times 8760(\mathrm{~h} / \text { year }) \times 0.2 \times 0.7 \times 10^{-6}
$$

where $D(\mathrm{nGy} / \mathrm{h})$ is the calculated dose rate, $0.7(\mathrm{~Sv} / \mathrm{Gy})$ is the conversion coefficient from the absorbed dose rate in air to the effective dose rate and 0.2 is the outdoor occupancy factor [11].

Table 1 shows the absorbed and effective dose rate. The average absorbed and effective dose rates are 25.7 $\mathrm{nGy} / \mathrm{h}$ and $0.23 \mathrm{mSv} / \mathrm{year}$ respectively. The highest value of the dose rate is for Sample (15), $51.20 \mathrm{nGy} / \mathrm{h}$ and the minimum value is for Sample (1), $4.31 \mathrm{nGy} / \mathrm{h}$. The maximum effective dose rate is $0.45 \mathrm{mSv} /$ year and the minimum is $0.04 \mathrm{mSv} /$ year.

\subsection{Radium Equivalent Activity}

The distribution of ${ }^{238} \mathrm{U},{ }^{232} \mathrm{Th}$ and ${ }^{40} \mathrm{~K}$ in marbles is not uniform. Uniformity in respect of exposure to radiation

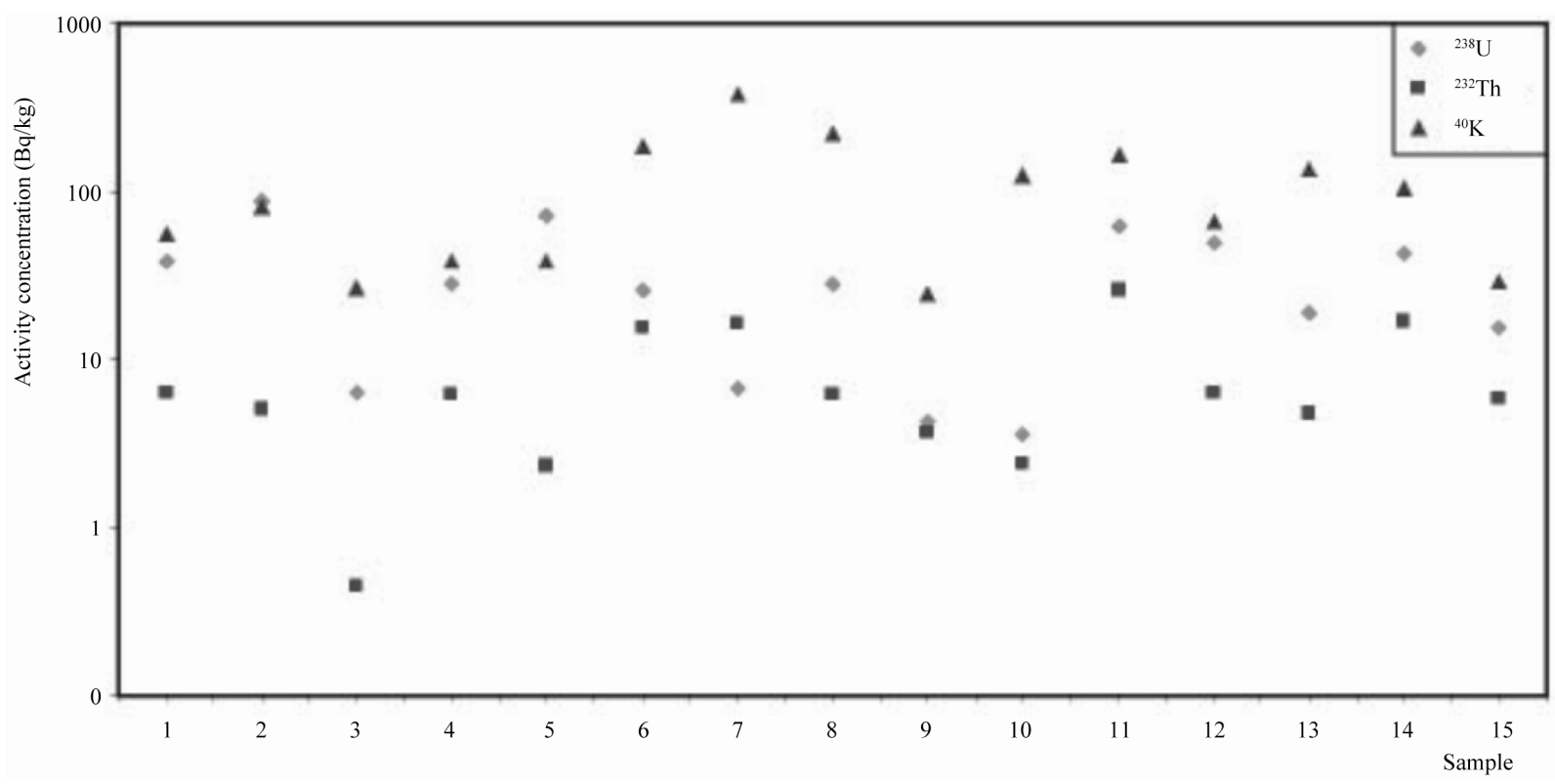

Figure 3. The activity concentrations for primordial radionuclides ${ }^{238} \mathrm{U},{ }^{232} \mathrm{Th}$ and ${ }^{40} \mathrm{~K}$. 
Table 1. Absorbed dose rate $(\mathrm{nGy} / \mathrm{h})$, effective dose rate (mSv/an), $H_{e x}, H_{i n}$ and $R_{\text {eq }}(B q / k g)$ for the marble samples.

\begin{tabular}{clccccc}
\hline No. & Commercial name & $D$ & $D_{\text {eff }}$ & $\mathrm{H}_{\text {ex }}$ & $\mathrm{H}_{\text {in }}$ & $\mathrm{Ra}_{\text {eq }}$ \\
\hline 1 & Thala beige & 4.31 & 0.04 & 0.05 & 0.04 & 9.04 \\
2 & Thala royal & 18.27 & 0.16 & 0.09 & 0.18 & 39.63 \\
3 & Thala imperial & 36.70 & 0.32 & 0.30 & 0.41 & 79.30 \\
4 & Thala noir & 29.18 & 0.26 & 0.21 & 0.24 & 62.15 \\
5 & Thala gris & 28.93 & 0.25 & 0.09 & 0.18 & 59.17 \\
6 & Gris foussana & 25.81 & 0.23 & 0.09 & 0.22 & 53.67 \\
7 & Chamtou & 5.24 & 0.05 & 0.05 & 0.04 & 11.35 \\
8 & Kadhel gris & 8.33 & 0.07 & 0.14 & 0.05 & 16.65 \\
9 & Kadhel rose & 51.20 & 0.45 & 0.21 & 0.47 & 110.9 \\
10 & Jaune moutard & 29.83 & 0.26 & 0.18 & 0.31 & 64.36 \\
11 & Courteau & 17.16 & 0.15 & 0.14 & 0.15 & 35.88 \\
12 & Noisette beige & 34.86 & 0.31 & 0.15 & 0.32 & 75.61 \\
13 & Gris Marmis & 11.95 & 0.11 & 0.10 & 0.11 & 26.01 \\
14 & Noir Aziza & 25.70 & 0.23 & 0.15 & 0.24 & 54.88 \\
15 & Marron Kesra & 51.20 & 0.45 & 0.30 & 0.51 & 110.9 \\
\hline
\end{tabular}

has been defined in terms of radium equivalent activity $\left(\mathrm{Ra}_{\mathrm{eq}}\right)$ in $\mathrm{Bq} / \mathrm{kg}$ to compare the specific activity of marbles containing different amounts of ${ }^{238} \mathrm{U},{ }^{232} \mathrm{Th}$ and ${ }^{40} \mathrm{~K}$. It is assumed that $370 \mathrm{~Bq} / \mathrm{kg}$ of ${ }^{238} \mathrm{U}, 259 \mathrm{~Bq} / \mathrm{kg}$ of ${ }^{232} \mathrm{Th}$ and $4810 \mathrm{~Bq} / \mathrm{kg}$ of ${ }^{40} \mathrm{~K}$ produce the same gamma dose rate [12]. A radium equivalent of $370 \mathrm{~Bq} / \mathrm{kg}$ in marbles will produce an exposure of about $1.5 \mathrm{mSv} /$ year to the inhabitants [11]. The radium equivalent activity which can be calculated by the following formulae [13,14]:

$$
\mathrm{Ra}_{\text {eq }}=\mathrm{A}_{\mathrm{U}}+\mathrm{A}_{\mathrm{Th}} \times 1.43+\mathrm{A}_{\mathrm{K}} \times 0.077
$$

where $A_{U}$ is the ${ }^{238} U$ activity concentration $(B q / k g), A_{T h}$ is the ${ }^{232} \mathrm{Th}$ activity concentration $(\mathrm{Bq} / \mathrm{kg})$ and $\mathrm{A}_{\mathrm{K}}$ is the ${ }^{40} \mathrm{~K}$ activity concentration $(\mathrm{Bq} / \mathrm{kg})$.

The average calculated $\left(\mathrm{Ra}_{\mathrm{eq}}\right)$ values for marble samples were ranging from 9.04 to $110.9 \mathrm{~Bq} / \mathrm{kg}$ with the average value of $54.88 \mathrm{~Bq} / \mathrm{kg}$.

\subsection{External and Internal Hazard Indices}

To estimate the radiation dose expected to be delivered externally if a building is constructed using marbles, the external hazard index $\left(\mathrm{H}_{\mathrm{ex}}\right)$, due to the emitted $\gamma$-rays, can be calculated using the following equation $[8,15]$ :

$$
\mathrm{H}_{\mathrm{ex}}=\mathrm{A}_{\mathrm{U}} / 370+\mathrm{A}_{\mathrm{Th}} / 259+\mathrm{A}_{\mathrm{K}} / 4810
$$

In addition to the external irradiation, radon and its daughter products are also hazardous to the respiratory organs. The internal exposure to radon and its short-lived products is proscribed by the internal hazard index $\left(\mathrm{H}_{\text {in }}\right)$. For the safe use of a marbles in the construction of dwellings $H_{\text {in }}$ should be less than unity. The Internal hazard index is calculated by the following formula [15-17]:

$$
\mathrm{H}_{\text {in }}=\mathrm{A}_{\mathrm{U}} / 185+\mathrm{A}_{\mathrm{Th}} / 259+\mathrm{A}_{\mathrm{K}} / 4810
$$

The calculated external and internal hazard indices values (Table 1) are ranged from 0.05 to 0.3 and from 0.04 to 0.51 respectively with an average value of 0.15 and 0.24 respectively.

\section{Conclusions}

Natural radioactivity of 15 samples of marbles collected in Tunisia was determined by gamma-ray spectrometry using hyper-pure germanium (HPGe) detector. In the case of uranium the highest level was found in the "Thala royal" marble sample and the lowest level in the "Gris Marmis" marble sample. For thorium the highest level was found in "Courteau" marble sample and the lowest level in "Thala imperial" marble sample, while for potassium the highest level was found in "Chamtou" marble and the lowest level in the "Kadhel rose" marble sample.

Based on the results obtained in this study for absorbed and effective dose rate, radium equivalent activity, external and internal hazard indices, we conclude that the radioactivity levels of marbles are within the international recommended values from world-wide areas due to terrestrial gamma radiation [11]. According to the recommended values and the calculated external and internal hazard indices values, the marble samples are acceptable for use as building materials and decoration.

\section{REFERENCES}

[1] M. A. Misdaq and A. Amghar, "Radon and Thoron Emanation from Various Marble Materials Impact on the Workers," Radiation Measurements, Vol. 39, No. 4, 2005, pp. 421-430. doi:10.1016/j.radmeas.2004.06.011

[2] A. J. A. H. Khatibeh, N. Ahmad, Matiullah and M. A. Kenawy, "Natural Radioactivity in Marble Stones, Jordan,” Radiation Measurements, Vol. 28, No. 1-6, 1997, pp. 345-348. doi:10.1016/S1350-4487(97)00097-8

[3] E. S. Larsen and D. Gottfried, "Uranium and Thorium in Selected Sites of Igneous Rocks," American Journal of Science, Bradley Volume, Vol. 258A, 1960, pp. 151-169.

[4] M. Brai, S. Basile, S. Bellia, S. Hauser, P. Puccio, S. Rizzo, A. Bartolotta and A. Licciardello, "Environmental Radioactivity at Stromboli (Aeolian Islands)," Applied Radiation and Isotopes, Vol. 57, No. 1, 2002, pp. 99-107. doi:10.1016/S0969-8043(02)00074-X

[5] IAEA, "Measurement of Radionuclides in Food and the Environment," Technical Report, Series No. 295, 1989, Vienna.

[6] R. R. Benke and K. J. Kearfott, "Soil Sample Moisture Content as a Function of Time during Oven Drying for Gamma-Ray Spectroscopic Measurements," Nuclear Instruments and Methods in Physics Research Section A: Accelerators, Spectrometers, Detectors and Associated 
Equipment, Vol. 422, No. 1-3, 1999, pp. 817-819. doi:10.1016/S0168-9002(98)01004-3

[7] A. S. Mollah, G. U. Ahmed, S. R. Hussain and M. M. Rahman, "The Natural Radioactivity of Some Building Materials Used in Bangladesh," Health Physics, Vol. 50, No. 6, 1986, pp. 849-851.

[8] A. M. El-Arabi, "Gamma Activity in Some Environmental Samples in South Egypt," Indian Journal of Pure and Applied Physics, Vol. 43, No. 6, 2005, pp. 422-426.

[9] C. Kohshi, I. Takao and S. Hideo, "Terrestrial Gamma Radiation in Koshi Prefecture, Japan,” Journal of Health Science, Vol. 47, No. 4, 2001, pp. 362-372. doi:10.1248/jhs.47.362

[10] M. Tzortzis, H. Tsertos, S. Christo and G. Christodoulides, "Gamma-Ray Measurements of Naturally Occurring Radioactive Samples from Cyprus Characteristic Geological Rocks," Radiation Measurements, Vol. 37, No. 3, 2003, pp. 221-229. doi:10.1016/S1350-4487(03)00028-3

[11] UNSCEAR, "Sources, Effects and Risks of Ionizing Radiation," United Nations Scientific Committee on the Effects of Atomic Radiation, New York, 2000.
[12] E. Stranden, "Some Aspects on Radioactivity of Building Materials,” Pyhsica Norvegica, Vol. 8, 1976, pp. 167-177.

[13] J. Beretka and P. J. Mathew, "Natural Radioactivity of Australian Building Materials, Industrial Wastes and by Products,” Health Physics, Vol. 48, No. 1, 1985, pp. 8795. doi:10.1097/00004032-198501000-00007

[14] M. Tufail, N. Ahmad, S. M. Mirza, N. M. Mirza and H. A. Khan, "Natural Radioactivity from the Building Materials Used in Islamabad and Rawalpindi, Pakistan," Science of the Total Environment, Vol. 121, 1992, pp. 283-291. doi:10.1016/0048-9697(92)90321-I

[15] R. Krieger, "Radioactivity of Construction Materials," Betonwerk Fertigteil Technik, Vol. 47, 1981, pp. 468-473.

[16] L. S. Quindos, P. L. Fernandez and J. Soto, "Building Materials as Source of Exposure in Houses," In: B. Seifert and H. Esdorn, Eds., Indoor Air '87, Institute for Water, Soil and Air Hygiene, Berlin, 1987, p. 365.

[17] E. Cottens, "Actions against Radon at the International Level," Proceedings of the Symposium on SRBII, Journee Radon, Royal Society of Engineers and Industrials of Belgium, Brussels, 17 January 1990. 